\title{
Samgar ben Anat onder die Rigters
}

\author{
S D Snyman \\ Departement Ou Testament \\ Universiteit van die Vrystaat
}

\begin{abstract}
Samgar ben Anat among the Judges

Shamgar ben Anath could be regarded as both isolated and ignored. He finds himself isolated between the two major judges, Ehud and Deborah, and for this reason is easily overlooked and ignored. Shamgar, although not an Israelite, should be considered as a judge in his own right. Shamgar is seen as the successor to Ehud. He has, as is the case with other judges, the responsibility of delivering the people and he makes use of whatever capabilities and skills he might possess. Theologically seen, one should rather regard it as Yahweh and the judges being simultaneously at work with Yahweh taking the most unlikely candidates with the most awkward weapons into his service to deliver his people time and again from the hardships of oppression.
\end{abstract}

\section{INLEIDING}

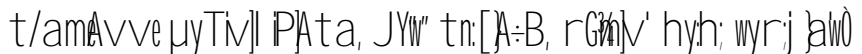

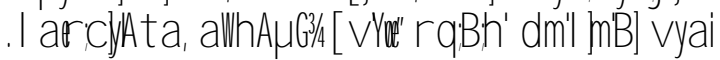

(Biblia Hebraica Stuttgartensia, 1990.)

"Na Ehud het Samgar seun van Anat opgetree. Hy het ses honderd Filistyne doodgeslaan met 'n sweepstok en vir Israel gered" (Rig 3:31; 1983 vertaling van die Bybel in Afrikaans).

"En na hom was daar Samgar ben Anat. Hy het ses honderd Filistyne verslaan met 'n aanporderstok/porstok. Ook hy het vir Israel gered" (eie vertaling).

Met die enkele vers word die loopbaan en optrede van die Rigter Samgar beskryf. Geen wonder nie dat die kort verhaal van Samgar al beskryf is as van die tergendste en fassinerende episodes in die boek Rigters (Shupak 1989:517). Van al die Rigters wat beskryf word in die boek Rigters, is Samgar die een van wie daar die minste besonderhede gegee word. Ander 
(kleiner) Rigters soos Tola (Rig 10:1-2), Jair (Rig 10:3-5), Ibsan (Rig 12:8-10), Elon (Rig 12:11-12) en Abdon (Rig12:13-15) kry ook min aandag, maar daar word veel meer biografiese en geografiese besonderhede gegee as wat by Samgar die geval is.

Die weergawe van Samgar se optrede kan as geïsoleerd en selfs geïgnoreerd beskryf word. Samgar se optrede staan enersyds geïsoleer tussen die optrede van Ehud en Debora wie se optrede uitvoerig en in detail beskryf word (Dirksen 1990:37; Burney 1970:75). Uit Rigters 4:1 lyk dit asof Samgar se optrede andersyds ook geïgnoreer word, want die betrokke vers verwys na die dood van Ehud, die Rigter wie se optrede pas voor Samgar beskryf word in Rigters 3:12-30 sonder enige verwysing na Samgar. Trouens, van Selms (1964:295) maak die opmerking dat die opmerking oor Samgar weggelaat kon word sonder om die kronologie van die boek enigsins te versteur.

By Samgar ontbreek daar inderdaad inligting wat by ander Rigters vertel word. Daar is geen aanduiding van die geografiese plek van Samgar se herkoms of optrede nie; daar is geen aanduiding van sy stamverband nie; daar is geen aanduiding van die duur van sy optrede nie; daar is geen aanduiding van waar hy te sterwe gekom en begrawe is nie; daar is geen aanduiding van sy familie, vrou of kinders nie; daar is geen aanduiding van 'n aanleidende oorsaak vir sy optrede as Rigter nie. Daar word nie gesê of daar vrede was na sy optrede soos by sommige van die ander Rigters nie.

Samgar is dus duidelik 'n enigma onder die Rigters. Dit laat die vraag ontstaan wat in hierdie bydra dan aan die orde gestel word: wat is die plek en teologiese funksie van Samgar in die Rigterboek?

Om die vraag te beantwoord gaan die vertelling oor Samgar in Rigters 3:31 eerstens literêr ondersoek word om sy plek in die boek as geheel vas te stel, tweedens gaan 'n historiese vraag gevra word na die persoon en identiteit van Samgar. Derdens gaan daar 'n paar teologiese gevolgtrekkings gemaak word uit die resultate van die ondersoek.

\section{SAMGAR IN DIE BOEK RIGTERS}

Die boek Rigters word gewoonlik verdeel in drie dele: ' $n$ proloog, ' $n$ middel gedeelte en 'n slot. Hoewel daar verskil van mening onder geleerdes is, kan die boek breedweg verdeel word in Rigters 1:1-2:5 as die proloog; Rigters 2:616:31 as die middelste gedeelte met Rigters $17-21$ as die slotdeel van die boek (Soggin 1981:4-5; Dirksen 1990:10). Die middelste deel van die boek is die deel wat vertel van die optrede van 'n reeks van Rigters of leiers van die volk Israel wat in die tyd na die inbesitname van die land en voor die instelling van die monargie leiding geneem het. 
Die narratiewe wat in Rigters 2:6-16:31 vertel word, kan tipeer word as 'n reeks van helde-verhale wat vertel van dapperheid en kloekmoedige optrede teen die oorweldigende mag van onderdrukkers. Tegelykertyd is daar ook 'n tweede onderliggende motief van teologiese didaktiek in die verhale teenwoordig (Birch 1999:206). Israel moet rekening hou met die werklikheid van Jahwe in hulle lewe. Wanneer hulle die Baäls en die Astartes dien, doen hulle wat verkeerd is in die oë van die Here (Rig 2:11) en tree Hy dan op teen sy volk deur hulle oor te gee "aan die vyande in die omgewing" (Rig 2:14) met die gevolg dat die Israeliete "baie swaar gekry" het (Rig 2:15). Jahwe voorsien egter leiers om die volk te red uit die mag van die vyande. Die leiers is die Rigters wat die helde is in die helde-verhale van Rigters 3:7-16:31. Die heldeverhale word dus meer as helde-verhale in die Rigterboek, dit word ook getuienisse van Jahwe se aktiewe betrokkendheid by die lotgevalle van sy volk. Dit is binne die narratiewe konteks waarbinne die Samgar-verhaal gelees en geïnterpreteer moet word.

\subsection{Samgar onder die Rigters}

Ten spyte van Samgar se uitsonderlike posisie wat hom anders maak as die ander Rigters, is dit tog duidelik dat hy 'n Rigter is. Hy word derde in die ry van twaalf Rigters genoem. Alhoewel daar manuskripte is wat Rigters 3:31 na Rigters 16:31 (dus na die optrede van Simson) plaas, is daar geen oortuigende redes daarvoor nie (Scherer 2002:107-108). Die Samgarvertelling vind sy plek in Rigters 3 voor die optrede van Debora en Barak, waarskynlik na aanleiding van die verwysing na Samgar in Rigters 5:6. Dit is verder interessant om daarop te let dat die sogenaamde "kleiner Rigters" in 'n verhouding van 1:2:3 gerangskik word in die boek Rigters (Samgar; Tola en Jaïr; Ibsan, Elon en Abdon).

Die woorde waarmee vers 31 begin, plaas Samgar duidelik as die opvolger van Ehud: wy j a w "en na hom" (Soggin 1981:58). Die kopulatiewe waw en die pronominale suffiks in die derde persoon manlik enkelvoudvorm het die onweerlegbare implikasie dat Samgar soos Ehud as Rigter opgetree het ten behoewe van die volk as iemand in diens van Jahwe (Rig 3:15). Die woorde wy j d' "na hom" word ook in die res van die boek gevind waarmee die verskillende Rigters se optrede aan mekaar verbind word (vgl Rig 10:1: "Na Abimelek"; Rig 10:3: "na hom"; Rig 12:8: "Na Jefta"; Rig 12:11: "na hom"; Rig 12:13: "na hom").

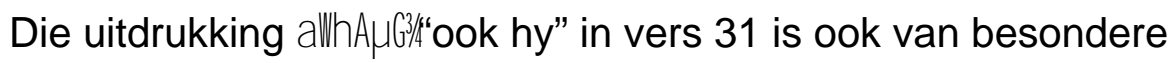
betekenis. Van Selms (1964:296) merk tereg op dat die uitdrukking uniek in die boek is. Van Selms (1964:296) interpreteer die uitdrukking dan verder deur daarop te wys dat die indruk met die uitdrukking gewek word dat die 


\section{Samgar ben Anat onder die Rigters}

vertelling oor Samgar maklik oorgesien kan word en dat daar met die uitdrukking eintlik klem geplaas word op die optrede van Samgar. Volgens van Selms (1964:294) word die woord "ook" gebruik wanneer daar die

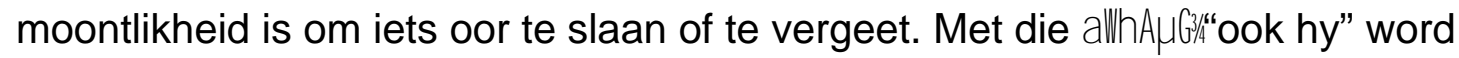
Samgar dus duidelik geposisioneer as Rigter ongeag en ten spyte van die min

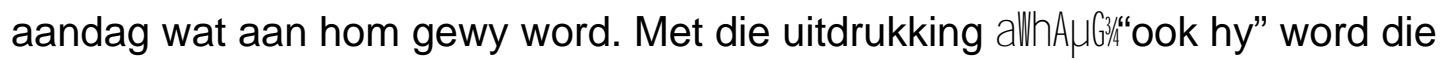
gevaar van isolering en ignorering dus enigsins getemper.

Daar is ' $n$ derde aanduiding in die teks wat Samgar bo alle twyfel as Rigter laat kwalifiseer: hy het Israel "gered" ([ v Yoe is die term wat in die teks gebruik word) of verlos (Klein 1988:101). Programmaties word dit die taak van die Rigters in hoofstuk 2. Wanneer die volk die gode van die nasies in die omgewing dien en die volk as gevolg daarvan oorgegee word in die mag van vyandige nasies, is dit die Here wat leiers na vore laat kom "om die volk te red" (Rig 2:16). Die Here se teenwoordigheid by die leiers was die waarborg dat die volk gered word uit die mag van hulle vyande (Rig 2:18). So is dit Otniël (Rig 3:9), Ehud (Rig 3:15), Gideon (Rig 8:33) en Tola (Rig 10:1) van wie dit telkens gesê word dat hulle die Israeliete gered het. In Rigters 10:1112 is daar ' $n$ verwysing na die Here wat die Israeliete gered het (onder andere) uit die mag van die Filistyne. Van Selms (1964:296) maak in die verband die terloopse opmerking dat die naam van die boek Rigters goedskiks ook "Verlossers" of "Redders" genoem kon word.

Samgar gebruik 'n d ml m sweepstok (aanporderstok) om die Filistyne mee te verslaan. Die Hebreeuse woord $\mathrm{d} \mathrm{ml}$ lm wat vertaal is met "sweepstok" is 'n hapax legomenon, maar daar is oor die algemeen konsensus onder geleerdes dat dit ' $n$ implement uit die boerdery milieu is wat bedoel word en dan meer spesifiek ' $n$ implement wat gebruik is in veeboerdery (Van Selms 1964:306; Burney 1970:77; Shupak 1989:523; Soggin 1981:57; Boling 1975:90). Dit is tipies vir Rigters om wapens van die een of ander aard te gebruik: Ehud het 'n swaard of dolk (Rig 3:16); Jael gebruik 'n tentpen en hamer om Sisera se kop te deurboor (Rig 4:21); Gideon se drie honderd manskappe gebruik 'n ramshoring, 'n leë erdekruik en 'n fakkel (Rig 7:16) en Simson gebruik die kakebeen van 'n donkie (Rig 15:15).

Samgar verslaan man alleen ses honderd Filistyne. Die getal ses honderd word gewoonlik verklaar as die getal soldate in 'n afdeling of bataljon. So byvoorbeeld lees ons in II Samuel 15:8 en in II Samuel 18:2 van soldate in Dawid se leër wat in afdelings van ses honderd gegroepeer was. Die getal moet dus ook nie letterlik opgeneem word nie as sou Samgar kop vir kop ses honderd Filistyne dood gemaak het nie. Die bedoeling van die teks is eerder dat hy ' $n$ afdeling of bataljon Filistyne van ses honderd man verslaan het. Getalle speel 'n belangrike rol in die boek Rigters. Telkens oorwin die 
Israeliete teen 'n oorweldigende oorwig van getalle. Gideon oorwin met 'n mag van drie honderd man en Simson neem op die dag van sy dood drie duisend Filistyne se lewens.

Genoeg om aan te toon dat alhoewel Samgar 'n uitsondering is onder die Rigters, hy tog voluit as een van die Rigters erken word (contra Soggin 1981:4 wat meen dat Samgar niks met die Rigters te doen het nie en wie se verhaal onverklaarbaar deel geword het van die teks). Opsommend dus: die enkele teks oor Samgar verbind hom met sy voorganger Ehud, daar word beklemtoon dat "ook hy" wat Samgar is, Israel gered het en om te red kan programmaties as die werk van 'n Rigter beskou word. Samgar gebruik soos die ander Rigters ook wapens en teen 'n oorweldigende getalle oorwig behaal hy tog ook oorwinning.

\subsection{Die identiteit van Samgar}

\subsubsection{Samgar ben Anat}

Die naam Samgar is nie 'n tipiese Hebreeuse naam nie (Dirksen 1990:37) wat dit dus 'n vraag maak of Samgar 'n Israeliet was (Burney 1970:76; Mayes 1974:76; Webb 1987:133; Craigie 1972:239). Sommige geleerdes dink aan 'n Hetitiese oorsprong van die naam (Burney 1970:76) terwyl ander weer dink aan 'n Hurritiese oorsprong van die naam (Soggin 1981:57; Craigie 1972:239; Boling 1975:89). Van Selms (1964:299) en ook Soggin (1981:57-58) verklaar die naam van Samgar as 'n kousatiewe saf-el formasie van die stamvorm $m$ $g-r$ wat dan iets sou kon beteken soos "die god(heid) maak hom onderworpe."

Dat Samgar aangedui word as $\operatorname{n[} A \div B$ "seun van Anat" is 'n verdere argument vir die standpunt dat Samgar nie 'n Israeliet was nie. Nadat daar aanvanklik gemeen is dat "bet Anat" 'n aanduiding van plek is (Van Selms 1964:301) is die konsensus onder geleerdes vandag anders. Anat is die naam van 'n Kanaänitiese godin en wat dit dus hoogs onwaarskynlik maak dat 'n Israeliet se naam 'n verwysing sou bevat na 'n god(in) van Kanaän. Anat was verder ook bekend as 'n godin van oorlog (Craigie 1972:239; Van Selms 1964:303; Shupak 1989:519) wat die militêre vermoë van Samgar om ses honderd Filistyne te verslaan onderstreep. Dat Samgar 'n Kanaäniet se militêre optrede teen die Filistyne verbind kon word met 'n Kanaänitiese godin van oorlog, is goed moontlik.

\subsubsection{Samgar 'n historiese persoon?}

Is daar aanduidings dat Samgar 'n historiese persoon was? Alhoewel daar geleerdes is wat die Samgar-verhaal beskou as 'n fiktiewe verhaal, gegrond op die patroon van Simson se stryd met die Filistyne (Shupak 1989:517), is 


\section{Samgar ben Anat onder die Rigters}

die tendens tans eerder in die rigting van 'n historiese verklaring van die Samgar-vertelling. Die verwysing na Samgar in Rigters 5:6 ("In die dae van Samgar seun van Anat, in die dae van Jael was die hoofpaaie stil") word gewoonlik gesien as 'n aanduiding dat Samgar inderdaad 'n historiese persoon was (Dirksen 1990:37; Burney 1970:75). Vir Soggin (1981:57) is die verwysing na Samgar in Rigters 5:6 'n aanduiding dat Samgar waarskynlik 'n wel bekende persoon was. Na 'n oorweging van tekste van Ras Shamra, Egipte en Mari is Craigie (1972:239-240) se versigtige gevolgtrekking dat Samgar moontlik 'n huursoldaat was. $\mathrm{Na}$ 'n gedetailleerde ondersoek na relevante bronne is Shupak (1989:523-524) se slotsom dat Samgar meer is as die vrug van die verbeelding van 'n Bybelse verteller van verhale, maar dat Samgar se verhaal 'n historiese basis vind aan die begin van Ystertydperk. Samgar ben Anat was bes moontlik 'n lid van 'n groep van 'Apiru huursoldate in diens van Ramses III en IV van Egipte.

Die verwysing na Samgar in Rigters 5:6 saam met Jael gee nie alleen 'n aanduiding van die historisiteit van Samgar nie, maar dit lei ook in die rigting van waar Samgar sy heldedaad verrig het. Die stamme onder bedreiging in Rigters 4-5 was Sebulon en Naftali wat stamme in die noorde van Palestina was. Volgens Rigters 4:11 het Geber die Keniet en die man van Jael wat Sisera doodgemaak het, naby Kedes, wat ook in die omgewing van Naftali in die noorde van die land is, kamp opgeslaan. Daar is getuienis dat alhoewel die Filistyne normaalweg met die suide van Palestina geassosieer word, hulle van die noorde af getrek het in die rigting van die suide waar hulle hulleself eventueel gevestig het (Shupak 1989:520-521; Van Selms 1964:304305) sodat dit nie histories onmoontlik is dat Samgar wel in 'n skermutseling met Filistyne was nie. Laastens kan daar verwys word na Rigters 10:11-12 waar daar na die redding van die Israeliete uit die mag van die Filistyne verwys word en wat goed moontlik 'n verwysing na Samgar se optrede en/of die optrede van Barak kan wees (Webb 1987:133, 247 voetnota 36).

Om dus op te som: Samgar ben Anat was 'n Kanaäniet wat in die noorde van Palestina as 'n soort huursoldaat teen die Filistyne opgetree het en wat as gevolg van die optrede en eventuele merkwaardige oorwinning van hom bekend geword het as die seun van Anat, 'n Kanaänitiese godin van oorlog.

Hierdie konsensus verklaar egter nie waarom Samgar, 'n beroepsmilitaris indien hy 'n huursoldaat was, nie van militêre wapens gebruik gemaak het om 'n mag van ses honderd Filistyne te verslaan nie. Die moontlikheid wat hier voorgestel word is dat Samgar nie 'n militaris was nie, maar eerder 'n veeboer wat met die landbou-implement wat hy in sy hande gehad het en waarmee hy kennelik vertroud was, by geleentheid 'n Filistynse 
afdeling of bataljon militêr verslaan het. $\mathrm{Na}$ aanleiding hiervan het hy as Kanaäniet die titel van "seun van Anat" gekry. Hierdie verklaring verhoog die onwaarskynlikheid van oorwinning en maak die oorwinning wat behaal is, des te merkwaardiger. Dit kan dan ook moontlik die rede wees waarom die kort vertelling sy weg tot in die boek Rigters gevind het: by geleentheid het 'n veeboer die magtige Filistyne met 'n landbou-implement wat vir diere gebruik word, verslaan!

\section{DIE TEOLOGIESE FUNKSIE VAN SAMGAR ONDER DIE RIGTERS}

Hoe belangrik die vrae na die literêre en historiese problematiek van 'n teks ook al is, daar moet ook deurgedring word na die teologiese uitsprake wat 'n teks wil maak.

\subsection{God en mens aktief in die boek Rigters}

Die verhouding tussen goddelike en menslike inisiatief in die boek Rigters is 'n interessante vraag. In die belangrike hoofstuk twee word gesê dat dit Jahwe is wat leiers na vore laat kom en dat hulle die volk red uit die mag van mense deur wie hulle beroof is (Rig 2:16). Jahwe voorsien dus die leiers wat die volk sou red en is in die sin aktief betrokke by wat gebeur. Rigters 2:18 sê verder dat Jahwe nie net leiers voorsien nie, hulle word ook verseker van sy teenwoordigheid by hulle. Die opvallende is dat Rigters 2:16 sê dat dit die leiers is wat die volk gered het uit die mag van die mense. Rigters 2:18 sê "... so het Hy (Jahwe) die volk gered uit die mag van hulle vyande." Daar is dus 'n samespel in die inisiatief van God en mens in die optrede van die Rigters.

Jahwe se teenwoordigheid by die Rigters word op twee maniere eksplisiet gesê. Jahwe verseker sy teenwoordigheid aan Rigters. In die proloog tot die optrede van die Rigters word Juda verseker van Jahwe se teenwoordigheid (Rig 1:19). Wanneer die Josefstam onder bedreiging is, word hulle ook verseker van Jahwe se teenwoordigheid (Rig 1:22). Soos reeds hierbo aangedui word Jahwe se teenwoordigheid ook aan die Rigters verseker (Rig 2:18). Die enigste Rigter wat in soveel woorde verseker word van Jahwe se teenwoordigheid, is Gideon (Rig 6:12,16), alhoewel ons ook lees dat Jefta die teenwoordigheid van die Here opgesoek het. Interessant genoeg kry Gideon ook die opdrag om met die krag wat hy het, die Israeliete te gaan red uit die mag van die Midianiete (Rig 6:14).

Benewens die versekering van Jahwe se teenwoordigheid, is Jahwe ook teenwoordig deur sy Gees wat telkens sommige van die Rigters in besit neem. Van Otniël, wat as 'n model-Rigter beskou kan word, word dit gesê dat die Gees van die Here op hom was (Rig 3:10). Dieselfde word ook van 


\section{Samgar ben Anat onder die Rigters}

Gideon (Rig 6:34), Jefta (Rig 11:29) en Simson (Rig 13:25, 14:6, 15:14) gesê. Daar is inderdaad verskillende toespelings in die verskillende vertellings van heldedade deur die Rigters wat daarop dui dat i(I)emand agter alles sit (Marais 1998:95). Jahwe gebruik onwaarskynlike kandidate met onwaarskynlike instrumente en teen alle verwagting in, word die volk tog gered (vgl 3.2 en 3.3).

Jahwe en die Rigters is dus beide aktief aan die werk in die boek Rigters. Om van 'n jukstaposisie as 'n teenoorstelling van goddelike en menslike handelinge of aktiwiteite te praat, soos Klein (1988:32), is egter te skerp gestel. Veel eerder moet gedink word aan wat Marais (1998:95) meervoudige oorsaaklikheid noem. Hiervolgens is die handelinge van die verskillende Rigters tegelykertyd die handelinge van die Rigters, maar ook nie. Net so is die handelinge van Jahwe tegelykertyd sy handelinge, maar ook nie (Marais 1998:95-96). Wat die Rigters doen, is ook Jahwe se handelinge en wat Jahwe doen, is ook die handelinge van die Rigters. Die teenwoordigheid van Jahwe en sy bekragtiging van die Rigters deur sy Gees is nie genoeg nie - Rigters moet ook hulle eie inisiatief en bekwaamheid gebruik. Net so is die eie inisiatief en planne van die Rigters nie genoeg nie Jahwe se teenwoordigheid en sy Gees is nodig vir die suksesvolle redding van die volk.

In die geval van Samgar sal dit ook nie anders wees nie. Al word daar niks pertinent van Jahwe se handelinge in die optrede van Samgar gesê nie, beteken dit nie Jahwe is afwesig wanneer Samgar optree nie. Jahwe is juis daar waar mense meen dat Hy (dalk) nie is nie. Wat Samgar egter tog uitsonder, is die aanduiding dat hy nie 'n Israeliet is nie. Jahwe handel ook met nie-Israeliete om sy volk te red.

\subsection{Jahwe maak gebruik van die onwaarskynlikste kandidate om Rigters te wees}

Mense wat optree as Rigters is die meer onwaarskynlike kandidate. Daar is reeds aangetoon hoedat Samgar 'n nie-Israeliet is, maar wat voluit as Rigter gereken word. Dieselfde kan van die ander Rigters ook gesê word. Ehud is linkshandig (meer letterlik: beperk in sy regterhand; Klein 1988:37; Webb 1987:130) en linkshandigheid is gesien as 'n swakheid en abnormaliteit in die omgewing van Israel. Debora is 'n vrou wat optree as Rigter en die krag agter Barak is. Dit is interessant genoeg ook nie Barak nie, maar Jael, 'n vrou, wat eventueel vir Sisera, die hoof van Jabin se leër, om die lewe bring. Gideon is 'n twyfelaar wat aan die einde van sy Rigterskap faal. Jefta is die seun van 'n prostituut en wat deur sy broers uit die familiekring weggejaag word en wat hom onseker en self-gesentreerd maak (Webb 1987:75). Simson is iemand 
wat weinig respek het vir nasireërskap, hy het 'n swakheid vir vroue en is iemand wat aan die einde van sy lewe 'n ietwat patetiese figuur slaan as 'n persoon wat blind is en verneder deur die aartsvyande van die Israeliete. Rigters 2:11-16:31 bevat heldeverhale maar dan is dit "helde" anders as wat gewoonlik met die begrip "held" verstaan word. Die Rigters is onwaarskynlike kandidate om werklik helde te wees en tog word die onwaarskynlike kandidate tog helde deur hulle optrede teen vyandelike magte.

\subsection{Jahwe gebruik die bekwaamhede van die onwaarskynlike kandidate}

Hoe onwaarskynlik die kandidate is om as Rigters hulle werk te doen, elkeen van hulle het bekwaamhede wat diensbaar is vir Jahwe se wil om sy volk telkens te red. Samgar is 'n veeboer wat bekwaam is om 'n sweepstok as 'n doeltreffende wapen te gebruik en 'n hele bataljon Filistyne mee te verslaan. Ehud gebruik juis sy linkshandigheid as 'n pluspunt om 'n suksesvolle sluipmoord op 'n koning uit te voer. Ehud is ook bekwaam in sy gebruik van woorde om die koning uit te lok om die geheime woord/ding van Ehud te verneem. Debora is 'n vrou met besondere leierseienskappe wat soveel gesag afdwing dat Barak gewillig gehoorsaam is in alles wat Debora vra en beplan. Jefta se onderhandelings vaardighede word goed benut in sy gesprekke met die Ammoniete en Simson se krag is legendaries.

\subsection{Jahwe maak gebruik van die onwaarskynlikste instrumente in die hande van onwaarskynlike kandidate}

Samgar maak gebruik van 'n sweepstok (aanporderstok). Juis by die gebruik van Samgar se instrument is daar 'n interessante ironie by betrokke. Die instrument wat Samgar gebruik is 'n malmed $(\mathrm{d} \mathrm{ml} / \mathrm{m})$ in Hebreeus. Letterlik vertaal beteken die term "'n instrument van instruksie of lering" (Klein 1988:39). Niemand kan dit betwyfel dat Samgar met sy "instrument van instruksie" die Filistyne 'n paar dinge geleer het nie! Ehud maak gebruik van 'n swaard. Jael gebruik 'n tentpen en hamer. Gideon gebruik 'n ramshoring, 'n leë erdekruik en 'n fakkel. Simson gebruik 'n kakebeen van 'n esel. Hierdie gemeenskaplike motief bind die verhale nie net aan mekaar nie, maar soms antisipeer die gebruik van een instrument die gebruik van 'n volgende instrument (Webb 1987:178). By haas elke verhaal gebeur die onwaarskynlike, teen die verwagting in. Teenoor 'n oorweldigende getalle oorwig, behaal die verskillende Rigters telkens 'n oorwinning ten spyte van onortodokse metodes en instrumente wat as onwaarskynlike wapens moet diens doen. Dit is 'n bevestiging van die gelyktydige samespel van goddelike en menslike handelinge in die boek. 


\subsection{Die boek Rigters as deel van die Deuteronomistiese Geskiedswerk}

Die boek Rigters vorm deel van die Deuteronomistiese Geskiedswerk (Von Rad 1975:307), wat breedweg beskou, 'n teologiese antwoord wil bied op die vraag na die katastrofe van die ballingskap wat konkreet vir Israel die verlies van die land beteken het. Die antwoord wat gegee word is dat die skuld vir die ballingskap nie aan Jahwe toegeskryf kan word nie; trouens Hy was getrou in sy verbondsverpligtinge teenoor die volk. Die oorsaak van die ballingskap lê eerder in die sonde van die volk. Hulle was ontrou aan Jahwe en ongehoorsaam aan die bepalings van die verbond. Hierdie teologiese waarheid word goed geillustreer in die boek Rigters. Telkens is dit die volk wat ander gode aanbid en so ontrou word aan Jahwe en telkens is dit Jahwe wat 'n Rigter voorsien om sy volk te red (Birch 1999:206-207). Die heldeverhale van die Rigters pas goed in by die teologie. Dit is Jahwe wat Rigters voorsien, ten spyte van die sonde van die volk en deur 'n samespel van Jahwe en die Rigters word die volk telkens gered.

\section{SLOT}

Die enkele vers in Rigters 3:31 wat die optrede van Samgar ben Anat vertel, staan dus nie verniet in die Ou Testament nie. Sonder die verhaal van Samgar ben Anat sou ons teologies armer gewees het. "Ook hy" is 'n Rigter wat as onwaarskynlike kandidaat ('n nie-Israeliet) vir Israel "gered" het met die onwaarskynlike wapen van 'n "aanporderstok", terwyl Jahwe in dit alles ook aktief teenwoordig was.

\section{EPILOOG}

Ek huldig met hierdie bydrae graag 'n gerespekteerde en gewaardeerde kollega in die gilde van Ou-Testamentici. Sy kritiese beoefening van die wetenskap van die Ou Testament, sy enorme kennis van die Ou Testament en sy vermoë om 'n teks noukeurig te lees en te vertaal laat 'n blywende invloed op die manier waarop ons met die Ou Testament omgaan. Soos wat die Rigterboek goeie verhale vertel en die verhale ook goed vertel, is Andries Breytenbach ook 'n storieverteller van formaat wat met anekdotes, legendes en verhale (sommige waar en ander miskien minder waar) ons eindeloos vermaak. Naas sy werk en roeping as predikant en Ou-Testamentikus is hy ook veeboer. My wens is dat hy die onopvallende en daarom half vergete verhaal van 'n veeboer in die Rigterboek opnuut sal waardeer wanneer hy na sy emeritaat meer veeboer as Ou-Testamentikus gaan wees. 


\section{Literatuurverwysings}

Biblia Hebraica Stuttgurtensia 1990. Stuttgart: Deutsche Bibelgesellschaft.

Birch B C, Brueggemann, W, Fretheim, T E \& Petersen, D L 1999. A theological introduction to the Old Testament. Minneapolis, MN: Fortress.

Boling, R G 1975. Judges introduction, translation and commentary. New York: Doubleday. (Anchor Bible.)

Burney, C F 1970. The Book of Judges with introduction and notes on the Hebrew text of the book of Kings with an introduction and appendix. New York: Ktav Publishing House.

Craigie, P C 1972. A Reconsideration of Shamgar ben Anath (Judg 3:31 \& 5:6). JBL 91(2), 239-240.

Dirksen, P B 1990. Richteren: Een praktischse bijbelverklaring. Kampen: Kok. (Tekst en Toelichting.)

Klein, L R 1988. The triumph of irony in the Book of Judges. Sheffield: Almond Press. (JSOT SS 68.)

Marais, J 1998. Representation in Old Testament narrative texts. Leiden: Brill. (Biblical Interpretation Series.)

Mayes, A D H 1974. Israel in the period of the Judges. London: SCM. (Studies in Biblical Theology.)

Scherer, A 2002. Simson und Shamgar: Zur Frage nach der ursprunglichen Position der Shamgarnotiz im Richterbuch. ZAW 114(1), 106-109.

Shupak, N 1989. New Light on Shamgar ben 'Anath. Biblica 70(4), 517-525.

Soggin, J A 1981. Judges a commentary. London: SCM. (Old Testament Library.)

Van Selms, A 1964. Judge Shamgar. Vetus Testamentum 14(3), 294-309.

Von Rad, G 1975. Old Testament Theology, vol I. London: SCM. (Old Testament Library.)

Webb, B G 1987. The Book of Judges: An integrated reading. Sheffield: JSOT Press. (JSOT SS 46.) 